\title{
MATRIKS BERSIH KUAT ATAS RING DERET PANGKAT TERGENERALISASI MIRING
}

\author{
AHMAD FAISOL, FITRIANI \\ Jurusan Matematika, \\ Fakultas Matematika dan Ilmu Pengetahuan Alam, Universitas Lampung, \\ Bandar Lampung, Indonesia.email : ahmadfaisol@fmipa.unila.ac.id, \\ fitriani.1984@fmipa.unila.ac.id
}

Diterima 12 Juni 2021 Direvisi 22 Juni 2021 Dipublikasikan 26 Juli 2021

\begin{abstract}
Abstrak. Salah satu konsep dalam teori aljabar yang banyak digunakan adalah matriks atas lapangan (field). Dalam perkembangannya, konsep matriks atas lapangan diperumum menjadi matriks atas ring. Ring merupakan suatu sistem matematika yang terdiri dari suatu himpunan tak kosong yang dilengkapi dua operasi biner yang memenuhi beberapa aksioma. Ring yang banyak digunakan dalam kajian ilmu matematika terapan adalah Ring Polinomial $R[X]$ dan Ring Deret Pangkat $R[[X]]$. Salah satu sifat matriks atas ring yang telah dikaji oleh para peneliti adalah syarat cukup matriks atas ring $R[[X]]$ merupakan matriks bersih kuat. Pada perkembangannya, struktur $R[[X]]$ digeneralisasi menjadi ring semigrup $R[S]$, Ring Deret Pangkat Tergeneralisasi (RDPT) $\left[\left[R^{S, \leq}\right]\right]$, dan Ring Deret Pangkat Tergeneralisasi Miring (RDPTM) $R[[S, \leq, \omega]]$. Berdasarkan fakta bahwa struktur $R[[S, \leq, \omega]]$ lebih umum dari $R[[X]]$, pada penelitian ini diberikan syarat cukup matriks atas RDPTM $R[[S, \leq, \omega]]$ merupakan matriks bersih kuat. Hal ini dapat dilakukan dengan cara menambahkan beberapa syarat pada struktur ring $R$, monoid terurut tegas $(S, \leq)$, dan homomorfisma monoid $\omega$ sehingga matriks atas $R[[S, \leq, \omega]]$ merupakan matriks bersih kuat. Sebagai akibat langsung, hasil penelitian ini lebih umum dari syarat cukup matriks atas $R[[X]]$ merupakan matriks bersih kuat yang telah dikaji sebelumnya.
\end{abstract}

Kata Kunci: Matriks atas ring, matriks bersih kuat, ring deret pangkat tergeneralisasi miring

\section{Pendahuluan}

Matriks didefinisikan sebagai susunan objek-objek matematika dalam baris dan kolom yang berbentuk persegi panjang yang diapit oleh kurung siku atau kurung biasa [1]. Objek-objek matematika ini disebut entri matriks. Matriks yang biasa dikenal adalah matriks dengan entrinya merupakan anggota lapangan (field), contohnya himpunan bilangan real $R$. Selanjutnya, matriks ini dikenal sebagai matriks atas lapangan. Karena struktur ring lebih umum dari lapangan, suatu matriks atas lapangan dapat diperumum menjadi matriks atas ring [2]. Ring adalah sebarang himpunan tak kosong yang dilengkapi dua operasi biner serta memenuhi beberapa aksioma tertentu [3]. Contoh ring yang terkenal adalah Ring Deret Pangkat Tergeneralisasi $(\mathrm{RDPT})\left[\left[R^{S, \leq}\right]\right]$ yang dikonstruksi oleh Ribenboim pada tahun 1990 
[4]. RDPT $\left[\left[R^{S, \leq}\right]\right]$ merupakan perumuman dari ring semigrup $R[S]$ [5], ring polinomial $R[X]$ dan ring deret pangkat $R[[X]][6]$. RDPT $\left[\left[R^{S, \leq}\right]\right]$ dikonstruksi dengan mensyaratkan $\operatorname{supp}(f)$ pada himpunan terurut parsial $(S, \leq)$ bersifat Artin dan narrow.

Himpunan tak kosong $S$ yang dilengkapi dengan relasi urutan parsial $\leq$ disebut himpunan terurut parsial (partially ordered set) $(S, \leq)$ [7]. Himpunan terurut parsial $(S, \leq)$ dikatakan Artin jika setiap barisan terurut tegas dari elemen $S$ berhingga, sedangkan dikatakan narrow jika setiap subhimpunan $S$ yang terurut trivial berhingga [8]. Beberapa penelitian terkait sifat-sifat RDPT $\left[\left[R^{S, \leq}\right]\right]$ juga telah dikaji oleh Ribenboim ([9][10][11][12][13][14]). Telah diketahui bahwa, suatu ring dapat dipandang sebagai modul atas dirinya sendiri. Pada tahun 2001, Varadarajan [15] menkonstruksi Modul Deret Pangkat Tergeneralisasi (MDPT) $M[[S]]$, yang merupakan modul atas RDPT $\left[\left[R^{S, \leq}\right]\right]$. Lebih lanjut, beberapa penelitian terkait struktur MDPT $M[[S]]$ dapat dilihat pada [16],[17],[18],[19],[20]. Pada tahun 2008, struktur RDPT $\left[\left[R^{S, \leq}\right]\right]$ diperumum oleh Mazurek dan Ziembowski dengan menggunakan homomorfisma monoid $\omega: S \rightarrow \operatorname{End}(R)$ pada operasi pergandaan konvolusi yang ada pada $\mathrm{RDPT}\left[\left[R^{S, \leq}\right]\right] 5[21]$. Generalisasi RDPT ini, selanjutnya disebut Ring Deret Pangkat Tergeneralisasi Miring (RDPTM) $R[[S, \leq, \omega]]$. Beberapa sifat terkait struktur RDPTM juga telah dikaji oleh Mazurek, dkk. ([22],[23],[24],[25],[26]). Di sisi lain, sifat-sifat yang berlaku pada RDPTM $R[[S, \leq, \omega]]$ juga dapat dilihat pada [27],[28],[29],[30],[31],[32],[33].

Pada tahun 2016, Chen dkk. [34] telah mengkaji struktur matriks atas ring deret pangkat $R[[X]]$ serta menentukan syarat cukup matriks tersebut merupakan matriks bersih kuat. Syarat cukup matriks atas $R[[X]]$ merupakan matriks bersih kuat, diperoleh dengan cara menambahkan syarat cukup pada matriks bersih kuat atas ring lokal [35] dan ring komutatif lokal $R$ [36][37]. Telah dijelaskan sebelumnya bahwa RDPTM $R[[S, \leq, \omega]]$ merupakan struktur ring yang lebih umum dari RDPT $\left[\left[R^{S, \leq}\right]\right.$, ring semigrup $R[S]$, ring deret pangkat $R[[X]]$, dan ring polinomial $R[X]$.

Pada tahun 2021, Rugayah dkk. [38] telah mengkaji struktur matriks atas RDPTM $R[[S, \leq, \omega]]$. Oleh karena itu, terbuka peluang yang cukup luas untuk menentukan syarat cukup matriks atas RDPTM $R[[S, \leq, \omega]]$ merupakan matriks bersih kuat. Hal ini dapat dilakukan dengan cara memperumum syarat cukup matriks bersih kuat atas $R[[X]]$ yang telah dikaji oleh Chen dkk. Sebagai akibat langsung dari penelitian ini, penelitian Chen dkk. merupakan hasil yang lebih khusus dari hasil penelitian ini.

\section{Landasan Teori}

\subsection{Matriks Bersih Kuat}

Pada bagian ini akan diberikan pengertian tentang ring bersih dan matriks bersih kuat atas ring.

Diberikan ring $R$ dengan elemen satuan. Himpunan semua elemen idempotent $R$ dinotasikan dengan $\operatorname{Id}(R)$, sedangkan himpunan semua elemen unit $R$ dinotasikan dengan $U(R)$. Elemen $x \in R$ disebut bersih (clean) jika $x=u+e$ untuk suatu $u \in$ $U(R)$ dan $e \in I d(R)$. Sebarang ring $R$ disebut bersih (clean) jika setiap elemennya 
bersih. Selanjutnya, jika $\mathrm{R}$ ring bersih, maka $R[[X]]$ juga ring bersih [39].

Matriks berukuran $n \times n$ atas ring $R$ dinotasikan dengan $A_{n}$, dan matriks $n \times n$ atas ring deret pangkat $R[[X]]$ dinotasikan dengan $A_{n}[[X]]$. Selanjutnya, himpunan semua matriks berukuran $n \times n$ atas $R$ dan $R[[X]]$ berturut-turut didefinisikan oleh

$$
M_{n}(R)=\left\{A_{n}=\left[a_{i j}\right] \mid a_{i j} \in R ; i, j=1,2, \cdots, n\right\},
$$

dan

$$
M_{n}(R[[X]])=\left\{A_{n}[[X]]=\left[p_{i j}\right] \mid p_{i j} \in R[[X]] ; i, j=1,2, \cdots, n\right\} .
$$

Selanjutnya, didefinisikan $A[[0]]=\left[a_{i j}\right] \in M_{n}(R[[X]])$, dengan $a_{i j}$ adalah koefisien utama (leading coefficient) dari entri-entri matriks $A_{n}[[X]] \in M_{n}(R[[X]])$. Oleh karena itu, $A[[0]] \cong A_{n} \in M_{n}(R)$.

Sebarang matriks $A_{n}$ atas ring $R$ dikatakan bersih kuat (strongly clean) jika dapat dinyatakan sebagai penjumlahan matriks idempotent dan matriks invertible yang komutatif [35]. Karakterisasi matriks atas ring deret pangkat $R[[X]]$ merupakan matriks bersih kuat diberikan oleh teorema berikut.

Teorema 2.1. [34] Misalkan $R$ sebarang ring dan $A_{n}[[X]] \in M_{n}(R[[X]])$ untuk $n \geq 1$. Pernyataan berikut ekuivalen.

(1) $A_{n}[[0]] \in M_{n}(R)$ adalah matriks bersih kuat.

(2) $A_{n}[[X]] \in M_{n}(R[[X]])$ adalah matriks bersih kuat.

\subsection{Ring Deret Pangkat Tergeneralisasi Miring}

Berikut ini diberikan konstruksi Ring Deret Pangkat Tergeneralisasi Miring (RDPTM) $R[[S, \leq, \omega]]$ yang pertama kali dikenalkan oleh Mazurek dan Ziembowski pada tahun 2008.

Diberikan monoid terurut tegas $(S, \leq)$, ring komutatif dengan elemen satuan $R$ dan homomorfisma monoid $\omega: S \rightarrow \operatorname{End}(R)$. Dibentuk himpunan $R^{S}=\{f \mid f:$ $S \rightarrow R\}$ dan $R[[S, \leq, \omega]]=\left\{f \in R^{S} \mid \operatorname{supp}(f)\right.$ Artin dan narrow $\}$, dengan $\operatorname{supp}(f)=$ $\{s \in S \mid f(s) \neq 0\}$.

Selanjutnya, bayangan homomorfisma monoid $\omega(s)$ dinotasikan dengan $\omega_{s}$ untuk setiap $s \in S$. Oleh karena itu, untuk setiap $s, t \in S$ berlaku $\omega_{s t}=\omega(s t)=$ $\omega(s) \omega(t)=\omega_{s} \omega_{t}$. Jika $0 \in S$ adalah elemen identitas di $S$, maka $\omega_{0}=i_{R}$ adalah elemen identitas di $\operatorname{End}(R)$. Terhadap operasi penjumlahan fungsi dan operasi pergandaan konvolusi yang didefinisikan oleh:

$$
\begin{aligned}
(f+g)(s) & =f(s)+g(s), \\
(f g)(s) & =\sum_{(x, y) \in \chi_{s}(f, g)} f(x) \omega_{x}(g(y)),
\end{aligned}
$$

untuk setiap $s \in S$ dan $f, g \in R[[S, \leq, \omega]]$, dengan himpunan

$$
\chi_{s}(f, g)=\{(x, y) \in \operatorname{supp}(f) \times \operatorname{supp}(g) \mid x y=s\}
$$

berhingga, $R[[S, \leq, \omega]]$ merupakan ring yang disebut Ring Deret Pangkat Tergeneralisasi Miring (RDPTM). 
Untuk sebarang $r \in R$ dan $s \in S$, didefinisikan pemetaan $c_{r}, f_{s} \in R[[S, \leq, \omega]]$ sebagai berikut:

$$
c_{r}(u)=\left\{\begin{array}{l}
r, u=0, \\
0, u \neq 0,
\end{array}\right.
$$

dan

$$
f_{s}(u)=\left\{\begin{array}{l}
1, u=s \\
0, u \neq s
\end{array}\right.
$$

untuk setiap $u \in S$.

Berdasarkan persamaan (2.4) dan (2.5), jelas bahwa $r \mapsto c_{r}$ merupakan penyisipan ring (ring embedding) dari $R$ ke $R[[S, \leq, \omega]]$, dan $s \mapsto f_{s}$ merupakan penyisipan monoid (monoid embedding) dari $S$ ke monoid multiplikatif (operasi komposisi) $R[[S, \leq, \omega]]$. Lebih lanjut, berlaku $f_{s} c_{r}=c_{\omega_{s}(r)} f_{s}$ untuk setiap $s \in S$ dan $r \in R$.

Contoh 2.2. [21] Berikut ini adalah contoh khusus RDPTM $R[[S, \leq, \omega]]$.

(1) Jika dipilih monoid $S=\mathbb{N} \cup\{0\}$ terhadap operasi penjumlahan biasa, urutan trivial $\leq$ pada $S$ dan homomorfisma monoid $\omega: S \rightarrow \operatorname{End}(R)$ dengan $\omega_{s}=i_{R}$ untuk setiap $s \in S$, maka RDPTM $R[[S, \leq, \omega]]$ merupakan ring polinomial $R[X]$.

(2) Jika dipilih monoid $S=\mathbb{N} \cup\{0\}$ terhadap operasi penjumlahan biasa, urutan biasa $\leq$ pada $S$ dan homomorfisma monoid $\omega: S \rightarrow \operatorname{End}(R)$ dengan $\omega_{s}=i_{R}$ untuk setiap $s \in S$, maka RDPTM $R[[S, \leq, \omega]]$ merupakan ring deret pangkat $R[[X]]$.

(1) Jika dipilih homomorfisma monoid $\omega: S \rightarrow \operatorname{End}(R)$ dengan $\omega_{s}=i_{R}$ untuk setiap $s \in S$, maka RDPTM $R[[S, \leq, \omega]]$ merupakan RDPT $\left[\left[R^{S, \leq}\right]\right]$.

Pada Contoh 2.2(3), struktur RDPTM $R[[S, \leq, \omega]]$ sama dengan struktur RDPT $\left[\left[R^{S, \leq}\right]\right]$. Lema berikut mejelaskan bahwa RDPT $\left[\left[R^{S, \leq}\right]\right]$ isomorfik dengan ring deret pangkat $R[[X]]$.

Lema 2.3. [12] Diberikan ring komutatif $R$ dengan elemen satuan dan himpunan terurut tegas $(S, \leq)$. Jika $S=\mathbb{N} \cup\{0\}$ dan $\leq$ adalah urutan biasa pada $S$, maka $\left[\left[R^{S, \leq}\right]\right] \cong R[[X]]$ dengan pemetaan $f \mapsto \sum_{n \geq 0} f(n) x^{n}$.

Syarat perlu dan cukup RDPT $\left[\left[R^{S, \leq}\right]\right]$ merupakan ring bersih telah diberikan oleh Liu pada tahun 2004, yaitu jika $(S, \leq)$ monoid terurut tegas yang bersifat $0 \leq s$ untuk setiap $s \in S$, maka $\left[\left[R^{S, \leq}\right]\right]$ bersih jika dan hanya jika $R$ bersih [40].

\section{Pembahasan}

Sebelum menentukan syarat cukup matriks atas RDPTM $R[[S, \leq, \omega]]$ merupakan matriks bersih kuat, terlebih dahulu diberikan definisi matriks atas $R[[S, \leq, \omega]]$ yang telah dikaji oleh Rugayah dkk. [38].

Selanjutnya, matriks $n \times n$ atas $\operatorname{RDPT}\left[\left[R^{S, \leq}\right]\right]$ dinotasikan dengan $A_{n}[[S]]$, dan matriks $n \times n$ atas RDPTM $R[[S, \leq, \omega]]$ dinotasikan dengan $A_{n}[[S, \omega]]$. Lebih lanjut, 
himpunan semua matriks berukuran $n \times n$ atas RDPT dan RDPTM berturut-turut didefinisikan oleh

$$
M_{n}\left(\left[\left[R^{S, \leq}\right]\right]\right)=\left\{A_{n}[[S]]=\left[f_{i j}\right] \mid f_{i j} \in\left[\left[R^{S,}\right]\right] ; i, j=1,2, \cdots, n\right\},
$$

dan

$$
M_{n}(R[[S, \leq, \omega]])=\left\{A_{n}[[S, \omega]]=\left[f_{i j}\right] \mid f_{i j} \in R[[S, \leq, \omega]] ; i, j=1,2, \cdots, n\right\} .
$$

Lema 3.1. Diberikan ring $R_{1}$ dan $R_{2}$. Jika $R_{1} \cong R_{2}$, maka $M_{n}\left(R_{1}\right) \cong M_{n}\left(R_{2}\right)$.

Bukti. Karena $R_{1} \cong R_{2}$, jelas terdapat isomorfisma $\mu: R_{1} \rightarrow R_{2}$. Didefinisikan pemetaan $\sigma: M_{n}\left(R_{1}\right) M_{n}\left(R_{2}\right)$ dengan

$$
\sigma\left(\left[a_{i j}\right]\right)=\left[\mu\left(a_{i j}\right)\right],
$$

untuk setiap $\left[a_{i j}\right]=A_{n} \in M_{n}\left(R_{1}\right)$. Akan ditunjukkan $\sigma$ merupakan isomorfisma.

(i) Untuk sebarang $A_{n}=\left[a_{i j}\right], B_{n}=\left[b_{i j}\right] \in M_{n}\left(R_{1}\right)$ dengan $a_{i j}, b_{i j} \in R_{1}$ untuk $i, j=1,2, \cdots, n$, akan ditunjukkan $\sigma\left(A_{n}+B_{n}\right)=\sigma\left(A_{n}\right)+\sigma\left(B_{n}\right)$ dan $\sigma\left(A_{n} B_{n}\right)=\sigma\left(A_{n}\right) \sigma\left(B_{n}\right)$. Dengan kata lain, akan ditunjukkan $\sigma$ merupakan homomorfisma. Karena berlaku

$$
\begin{aligned}
\sigma\left(A_{n}+B_{n}\right) & =\sigma\left(\left[a_{i j}\right]+\left[b_{i j}\right]\right)=\sigma\left(\left[a_{i j}+b_{i j}\right]\right), \\
& =\left[\mu\left(a_{i j}+b_{i j}\right)\right]=\left[\mu\left(a_{i j}\right)+\mu\left(b_{i j}\right)\right], \\
& =\left[\mu\left(a_{i j}\right)\right]+\left[\mu\left(b_{i j}\right)\right]=\sigma\left(\left[a_{i j}\right]\right)+\sigma\left(\left[b_{i j}\right]\right), \\
& =\sigma\left(A_{n}\right)+\sigma\left(B_{n}\right),
\end{aligned}
$$

dan

$$
\begin{aligned}
\sigma\left(A_{n} B_{n}\right) & =\sigma\left(\left[a_{i j}\right]\left[b_{i j}\right]\right)=\sigma\left(\left[\sum_{k=1}^{n} a_{i k} b_{i k}\right]\right), \\
& =\left[\mu\left(\sum_{k=1}^{n} a_{i k} b_{k j}\right)\right]=\left[\sum_{k=1}^{n} \mu\left(a_{i k} b_{k j}\right)\right] 7, \\
& =\left[\sum_{k=1}^{n} \mu\left(a_{i k}\right) \mu\left(b_{k j}\right)\right] ; \text { misalkan } \mu\left(a_{i k}\right)=c_{i k} \text { dan } \mu\left(b_{k j}\right)=d_{k j} . \\
& =\left[\sum_{k=1}^{n} c_{i k} d_{k j}\right]=\left[c_{i j}\right]\left[d_{i j}\right]=\left[\mu\left(a_{i j}\right)\right]\left[\mu\left(b_{i j}\right)\right], \\
& =\sigma\left(\left[a_{i j}\right]\right) \sigma\left(\left[b_{i j}\right]\right)=\sigma\left(A_{n}\right) \sigma\left(B_{n}\right),
\end{aligned}
$$

terbukti bahwa $\sigma$ merupakan homomorfisma.

(ii) Akan ditunjukkan $\sigma$ injektif, yaitu, untuk sebarang $A_{n}=\left[a_{i j}\right], B_{n}=\left[b_{i j}\right] \in$ $M_{n}\left(R_{1}\right)$ dengan $a_{i j}, b_{i j} \in R_{1}$ untuk $i, j=1,2, \cdots, n$, jika $\sigma\left(A_{n}\right)=\sigma\left(B_{n}\right)$, maka $A_{n}=B_{n}$. Jika $\sigma\left(A_{n}\right)=\sigma\left(B_{n}\right)$, maka $\sigma\left(\left[a_{i j}\right]\right)=\sigma\left(\left[b_{i j}\right]\right)$. Berdasarkan (3.1), diperoleh $\left[\mu\left(a_{i j}\right)\right]=\left[\mu\left(b_{i j}\right)\right]$. Dua matriks dikatakan sama jika entrientrinya sama, sehingga diperoleh $\mu\left(a_{i j}\right)=\mu\left(b_{i j}\right)$. Karena $\mu$ isomorfisma, maka jelas $\mu$ injektif. Akibatnya, $a_{i j}=b_{i j}$. Dengan kata lain, terbukti $A_{n}=B_{n}$. 
(iii) Akan ditunjukkan $\sigma$ surjektif, yaitu, untuk setiap $C_{n}=\left[c_{i j}\right] \in M_{n}\left(R_{2}\right)$ terdapat $A_{n}=\left[a_{i j}\right] \in M_{n}\left(R_{1}\right)$ sehingga $\sigma\left(A_{n}\right)=C_{n}$.

Karena $\mu$ isomorfisma, jelas bahwa $\mu$ surjektif. Oleh karena itu, untuk setiap $c_{i j} \in R_{2}$ terdapat $a_{i j} \in R_{1}$ sehingga $\mu\left(a_{i j}\right)=c_{i j}$ untuk setiap $i, j=1,2, \cdots, n$. Akibatnya, diperoleh $\left[\mu\left(a_{i j}\right)\right]=\left[c_{i j}\right]$. Berdasarkan (3.1), diperoleh $\sigma\left(\left[a_{i j}\right]\right)=\left[\mu\left(a_{i j}\right)\right]=\left[c_{i j}\right]$. Dengan kata lain, terbukti bahwa untuk setiap $C_{n}=\left[c_{i j}\right] \in M_{n}\left(R_{2}\right)$ terdapat $A_{n}=\left[a_{i j}\right] \in M_{n}\left(R_{1}\right)$ sehingga $\sigma\left(A_{n}\right)=C_{n}$. Jadi, $\sigma$ surjektif.

Dari (i) - (iii), terbukti bahwa $\sigma$ merupakan suatu isomorfisma. Dengan kata lain, terbukti bahwa $M_{n}\left(R_{1}\right) \cong M_{n}\left(R_{2}\right)$.

Proposisi 3.2. Diberikan ring komutatif $R$ dengan elemen satuan, monoid terurut tegas $(S, \leq)$, dan homomorfisma monoid $\omega: S \rightarrow \operatorname{End}(R)$. Jika $S=\mathbb{N} \cup\{0\}$, $\leq$ urutan biasa dan $\omega$ trivial, maka pernyataan berikut ekuivalen.

(1) $A_{n}[[0]] \in M_{n}(R)$ adalah matriks bersih kuat.

(2) $A_{n}[[X]] \in M_{n}(R[[X]])$ adalah matriks bersih kuat.

(3) $A_{n}[[S]] \in M_{n}\left(\left[\left[R^{S, \leq]]}\right)\right.\right.$ adalah matriks bersih kuat.

(4) $A_{n}[[S, \omega]] \in M_{n}(R[[S, \leq, \omega]])$ adalah matriks bersih kuat.

Bukti. $(1) \Rightarrow(2)$ Berdasarkan Teorema 2.1, terbukti bahwa jika $A_{n}[[0]] \in M_{n}(R)$ adalah matriks bersih kuat, maka $A_{n}[[X]] \in M_{n}(R[[X]])$ merupakan matriks bersih kuat.

$(2) \Rightarrow(3)$ Karena diketahui $S=\mathbb{N} \cup\{0\}$ dan $\leq$ adalah urutan biasa pada $S$, berdasarkan Lema 2.3 diperoleh $R[[X]] \cong\left[\left[R^{S, \leq]]}\right.\right.$. Selanjutnya, berdasarkan Lemma 3.1 diperoleh $M_{n}(R[[X]]) \cong M_{n}\left(\left[\left[R^{S, \leq}\right]\right]\right)$. Oleh karena itu, jika $A_{n}[[X]] \in$ $M_{n}(R[[X]])$ matriks bersih kuat, maka $A_{n}[[S]] \in M_{n}\left(\left[\left[R^{S, \leq}\right]\right]\right)$ merupakan matriks bersih kuat.

$(3) \Rightarrow(4)$ Karena diketahui $\omega$ trivial, $\operatorname{RDPTM} R[S, \leq, \omega]$ isomorfik dengan RDPT $\left[\left[R^{S, \leq}\right]\right]$. Akibatnya, berdasarkan Lema $3.1, M_{n}\left(\left[\left[R^{S, \leq}\right]\right]\right) \cong M_{n}(R[[S, \omega]])$. Dengan kata lain berlaku, jika $A_{n}[[S]] \in M_{n}\left(\left[\left[R^{S, \leq}\right]\right]\right)$ matriks bersih kuat, maka $A_{n}[[S, \omega]] \in M_{n}(R[[S, \leq, \omega]])$ merupakan matriks bersih kuat.

$(4) \Rightarrow(1)$ Berdasarkan persamaan (2.4), untuk setiap $s \in S$ berlaku

$$
\begin{aligned}
c_{r+t}(s) & =\left\{\begin{array}{l}
r+t, s=0, \\
0, \quad s \neq 0,
\end{array}=c_{r}(s)+c_{t}(s),\right. \\
c_{r t}(s) & =\left\{\begin{array}{ll}
r t, s=0, \\
0, & s \neq 0,
\end{array}=c_{r}(s) c_{t}(s) .\right.
\end{aligned}
$$

Dengan kata lain, untuk sebarang $r, t \in R$ dan $c_{r}, c_{t} \in R[[S, \leq, \omega]]$ berlaku $c_{r+t}=$ $c_{r}+c_{t}$ dan $c_{r s}=c_{r} c_{t}$.

Selain itu, dapat didefinisikan suatu pemetaan $\gamma: R \rightarrow R[[S, \leq, \omega]]$ dengan

$$
\gamma(r)=c_{r}
$$

untuk setiap $r \in R$ dan $c_{r} \in R[[S, \leq, \omega]]$. Pemetaan $\gamma$ merupakan homomorfisma 
karena untuk setiap $r, t \in R$ berlaku

$$
\gamma(r+t)=c_{r+t}=c_{r}+c_{t}=\gamma(r)+\gamma(t)
$$

dan

$$
\gamma(r t)=c_{r t}=c_{r} c_{t}=\gamma(r) \gamma(t) .
$$

Selain itu, jika $\gamma(r)=\gamma(t)$, maka $c_{r}=c_{t}$. Oleh karena itu, untuk setiap $s \in S$ berakibat $r=t$. Oleh karena itu, $\gamma$ merupakan monomorfisma. Selanjutnya, karena untuk setiap $c_{r} \in R[[S, \leq, \omega]]$ terdapat $r \in R$ sehingga $\gamma(r)=c_{r}$, akibatnya $\gamma$ merupakan epimorfisma. Dengan kata lain, $\gamma$ merupakan suatu isomorfisma atau $R \cong R[[S, \leq, \omega]]$. Berdasarkan Lema 3.1, diperoleh $M_{n}(R) \cong M_{n}(R[[S, \leq, \omega]])$. Akibatnya, jika $A_{n}[[S, \omega]] \in M_{n}(R[[S, \leq, \omega]])$ adalah matriks bersih kuat, maka $A_{n} \cong A_{n}[[0]] \in M_{n}(R)$ merupakan matriks bersih kuat.

\section{Kesimpulan}

Dari hasil yang telah diperoleh, dapat disimpulkan bahwa jika ring $R_{1}$ isomorfik dengan $R_{2}$, maka ring matriks $M_{n}\left(R_{1}\right)$ isomorfik dengan $M_{n}\left(R_{2}\right)$. Selanjutnya, jika diberikan ring $R$, monoid terurut tegas $S=\mathbb{N} \cup\{0\}$ terhadap operasi penjumlahan serta urutan biasa $\leq$, dan homomorfisma monoid $\omega: S \rightarrow \operatorname{End}(R)$ yang trivial, maka matriks atas RDPTM $A_{n}[[S, \omega]] \in R[[S, \leq, \omega]]$ merupakan matriks bersih kuat apabila $A_{n}[[0]] \cong A_{n} \in M_{n}(R)$ adalah matriks bersih kuat.

\section{Ucapan Terima kasih}

Penulis mengucapkan terimakasih yang sebesar-besarnya kepada Lembaga Penelitian dan Pengabdian kepada Masyarakat (LPPM) Universitas Lampung, yang telah mendanai penelitian ini dengan nomor kontrak No: 1648/UN 16 26.21/PN/2021.

\section{Daftar Pustaka}

[1] Anton, H., Rorres, C., 2005, Elementary Linear Algebra: Applications Version, $9^{\text {th }}$ Edition, New Jersey

[2] Brown, W.C., 1993, Matrices Over Commutative Rings, Marcel Dekker Inc., New York

[3] Dummit, D.S., 2004, Abstract Algebra, John Wiley and Sons

[4] Ribenboim, P., 1990, Generalized power series rings, Lattice, Semigroups and Universal Algebra, Plenum Press, New York, $271-277$

[5] Gilmer, R., 1984, Commutative Semigroups Rings, University of Chicago Press, Chicago

[6] Hungerford, T.W., 1974, Algebra, Springer-Verlag, New York

[7] Adkins, W. A., Weintraub, S. H., 1992, Algebra: an Approach via Module Theory, Springer-Verlag, New York.

[8] Elliott, G.A., Ribenboim, P., 1990, Fields of Generalized Power Series, Arch. Math., 54: 365 - 371

[9] Ribenboim, P., 1991, Rings of Generalized Power Series: Nilpotent Elements, Abh. Math. Sem. Univ. Hambg., 61: $15-33$ 
[10] Ribenboim, P., 1992, Noetherian Rings of Generalized Power Series, Journal of Pure and Applied Algebra, 79: 293 - 312

[11] Benhissi, A., Ribenboim, P., 1993, Ordered Rings of Generalized Power Series, Ordered Algebraic Structures

[12] Ribenboim, P., 1994, Rings of Generalized Power Series II: Units and ZeroDivisors, Journal of Algebra, 168: 71 - 89

[13] Ribenboim, P., 1995, Special Properties of Generalized Power Series, Journal of Algebra, 173: 566 - 586

[14] Ribenboim, P., 1997, Semisimple Rings and Von Neumann Regular Rings of Generalized Power Series, Journal of Algebra, 198: 327 - 338

[15] Varadarajan, K., 2001, Noetherian generalized power series rings and modules, Communications In Algebra, 29(1): 245 - 251

[16] Faisol, A., Surodjo, B., Wahyuni, S., 2019, The Relation between Almost Noetherian Module, Almost Finitely Generated Module and T -Noetherian Module, J. Phys.: Conf. Ser. 1306012001.

[17] Faisol, A., Surodjo, B., Wahyuni, S., 2019, The Sufficient Conditions for $R[X]$ module $M[X]$ to be $S[X]$-Noetherian, European Journal of Mathematical Sciences, $\mathbf{5}(1): 1-13$

[18] Faisol, A., Surodjo, B., Wahyuni, S., 2019, T[[S]]-Noetherian Property on Generalized Power Series Modules, JP Journal of Algebra, Number Theory and Applications, 43(1): $1-12$

[19] Pardede, W.A.P., Faisol, A., Fitriani, 2020, The $X[[S]]-S u b-E x a c t$ Sequence of Generalized Power Series Rings, Al-Jabar J. Pendidik. Mat., 11(2): 299 - 306

[20] Faisol, A., Fitriani, Sifriyani, 2021, Determining the Noetherian Property of Generalized Power Series Modules by Using X-Sub-Exact Sequence, Journal of Physics: Conf. Series 1751012028

[21] Mazurek, R., Ziembowski, M., 2008, On Von Neumann Regular Rings of Skew Generalized Power Series, Commun. Algebr., 36(5): 1855 - 1868

[22] Mazurek, R., Ziembowski, M., 2009, The ascending chain condition for principal left or right ideals of skew generalized power series rings, Journal of Algebra, 322(4): 983 - 994

[23] Mazurek, R., Ziembowski, M., 2010, Weak dimension and right distributivity of skew generalized power series rings, J. Math. Soc. Japan, 62(4): $1093-1112$

[24] Mazurek, R., 2014, Rota-Baxter Operators on Skew Generalized Power Series Rings, J. Algebr. its Appl., 13(7): $1-10$

[25] Mazurek, R., 2015, Left Principally Quasi-Baer and Left APP-rings of Skew Generalized Power Series, J. Algebr. its Appl., 14(3): $1-36$

[26] Mazurek, R., Paykan, K., 2017, Simplicity of skew generalized power series rings, New York J. Math. 23: 1273 - 1293

[27] Faisol, A., 2009, Homomorfisam Ring Deret Pangkat Teritlak Miring, J. Sains MIPA, 15(2): pp. $119-124$

[28] Faisol, A., 2010, Ideal Ring Deret Pangkat Teritlak Miring, Prosiding Seminar Nasional Sains MIPA dan Aplikasinya, 202 - 207

[29] Faisol, A., 2013, Pembentukan Ring Faktor Pada Ring Deret Pangkat Teritlak Miring, Prosiding Semirata FMIPA Universitas Lampung, 1 - 5

[30] Faisol, A., 2014, Endomorfisma Rigid dan Compatible pada Ring Deret Pangkat Tergeneralisasi Miring, J. Matematika, 17(2): 45 - 49

[31] Faisol, A., Surodjo, B., dan Wahyuni, S., 2016, Modul Deret Pangkat Ter- 
generalisasi Skew T-Noether, Prosiding Seminar Nasional Aljabar, Penerapan dan Pembelajarannya, 95 - 100

[32] Faisol, A., Surodjo, B., Wahyuni, S., 2018, The Impact of The Monoid Homomorphism on The Structure of Skew Generalized Power Series Rings, Far East Journal of Mathematical Sciences, 103(7): 1215 - 1227

[33] Faisol, A., Fitriani, 2019, The Sufficient Conditions for Skew Generalized Power Series Module $M[[S]$,$] to be T[[S]$,$] -Noetherian R[[S, \leq, \leq, \omega]]$-module, Al-Jabar J. Pendidik. Mat., 10(2): 285292

[34] Chen, H., Kose, H., Kurtulmaz, Y., 2016, Strongly Clean Matrices Over Power Series, Kyungpook Math. J. 56: 387 - 396

[35] Li, Y., 2007, Strongly clean matrix rings over local rings, Journal of Algebra, 312: $397-404$

[36] Borooaha, G., Diesl, A.J., Dorsey, T.J., 2008, Strongly clean matrix rings over commutative local rings, Journal of Pure and Applied Algebra, 212: 281 - 296

[37] Chen, H., Gurgun, O., Kose, H., 2013, Strongly clean matrices over commutative local rings, J. Algebra Appl., 12: 1250126 [13 pages]: 10.1142/S0219498812501265.

[38] Rugayah, S., Faisol, A., Fitriani, 2021, Matriks atas Ring Deret Pangkat Tergeneralisasi Miring, BAREKENG: J. Il. Mat. \& Ter., 15(1): 157 - 166

[39] Nicholson, W.K., 2005, Clean rings: A survey, Advances in Ring Theory, World Scientific Publishing, $181-198$

[40] Liu, Z., 2004, Special properties of rings of generalized power series, Comm. Algebra, 32(8): 3215 - 3226 